\title{
RISK ANALYSIS OF BOT CONTRACTS USING SOFT COMPUTING
}

\author{
Neda SHAHRARA ${ }^{\mathrm{a}}$, Tahir ÇELIK ${ }^{\mathrm{b}}$, Amir H. GANDOMI \\ ${ }^{a}$ Department of Civil Engineering, Eastern Mediterranean University, \\ Famagusta T.R. North Cyprus via Mersin 10, Turkey \\ ${ }^{b}$ Department of Civil Engineering, Cyprus International University, \\ Nicosia North Cyprus via Mersin 10, Turkey \\ ${ }^{c}$ BEACON Center for the Study of Evolution in Action, Michigan State University, East Lansing, MI 48824, USA
}

Received 24 Jan 2015; accepted 05 Mar 2015

\begin{abstract}
Build-Operate-Transfer (BOT) contracts have been widely implemented in developing countries facing budget constraints. Analysing the expected variability in project viability requires extensive risk analysis. An objective analysis of various risk variables and their influence on a BOT project evaluation requires study and integration of many scenarios into the concession terms, which is complicated and time-consuming. If the process of negotiating the financial parameters and uncertainties of a BOT project could be automated, this would be a milestone in objective decision-making from various stakeholders' points of view. A soft computing model would let the user incorporate as many scenarios as could be provided. Extensive risk analysis could then be easily performed, leading to more accurate and dependable results. In this research, an artificial neural network model with correlation coefficient of 0.9064 has been used to model the relationship between important project parameters and risk variables. This information was extracted from sensitivity analysis and Monte Carlo simulation results obtained from conventional spreadsheet data. The resulting consensus would yield to fair contractual agreements for both the government and the concession company.
\end{abstract}

Keywords: Build/Operate/Transfer, Monte Carlo simulation, risk analysis, artificial neural network, contracts.

\section{Introduction}

In recent years, awareness of the sustainability aspects of infrastructure projects has been increasing around the world. Making infrastructure projects technologically aware and adaptable to changes while meeting user needs normally increases total project cost (ASHRAE 2006). In some cases, government cannot afford the investment cost, but a public-private partnership (PPP) offers a better means to achieve the goal (Akintoye et al. 2003; Grimsey, Lewis 2004). Typically, government prefers to establish a long-term partnership to motivate the contractor to accelerate the construction phase and to consider the whole project life cycle to reduce energy consumption, minimize waste, and decrease operating and maintenance costs. This approach prevents the contractor from reducing short-term construction cost at the expense of longterm value (Grimsey, Lewis 2004; Yang et al. 2007).

The PPP type of agreement can be used in various sectors, including education, healthcare, transportation (parking facilities, airports, railroad facilities, trains, roads, and bridges), custodial infrastructure (detention facilities, courthouses), public buildings, water and wastewater utilities, defence installations, and IT facilities
(Akintoye 2009). One of the most popular PPP options is the Build-Operate-Transfer agreement (BOT), which takes a concession-based approach, meaning that the private partnership is based on the concept of a fixed-term concession, using various combinations of private-sector resources to design, construct, finance, renovate, operate, and maintain facilities (Grimsey, Lewis 2004). Ownership of the facility may remain with the government or be transferred to the government on completion of construction or at the end of the concession period at no cost and free of liens; the government will run the facility after the handover (Grimsey, Lewis 2004; Xenidis, Angelides 2005). In return, the concessionaire will recoup its capital investment from operating revenue during the concession period (Zhang, Kumaraswamy 2001).

BOT-type agreements are used in projects that require huge amounts of investment. Therefore determining the concession period and terms is of crucial importance to a successful agreement. According to $\mathrm{Ng}$ et al. (2007), entitling the concessionaire to increase tolls or tariffs to guarantee its own minimum revenue in the case of lower-than-expected project revenue (which is probable with a short concession period) would be repellent

Corresponding author: Amir H. Gandomi

E-mail: a.h.gandomi@gmail.com 
to users. On the other hand, a long concession period may well include the period of peak project serviceability, leaving no incentive for the government to continue operating the project after the handover. Therefore, the key to a successful PPP project implementation is a clear and mutually acceptable definition of concession terms (Liou, Huang 2008). Yang et al. (2007) proposed a model based on game theory and drew attention to the undeniable influence of project construction cost on concession terms. Their model did not specify toll/tariff rates or other fundamental parameters which define decisionmaking boundaries for the host government. $\mathrm{Ng}$ et al. (2007) applied fuzzy set theory to a simulation model to examine various scenarios and to achieve maximum IRR, minimum tariff regime, and minimum concession period simultaneously as an optimal scenario. IRR has certain drawbacks as a decision-making criterion, and because NPV is more objective, it is logical to perform project appraisal on both criteria to avoid misleading judgments (Jenkins et al. 2011).

To obtain consensus during a contract negotiation phase, various combinations of concession terms must be evaluated. This typically involves repeated recalculation of conventional financial analysis spreadsheets, which is a time-consuming and complex process. To alleviate this problem, Ngee et al. (1997) developed an automated mechanism to expedite the negotiation process between the government and the concessionaire. Using multiple linear regression analysis, they obtained a predictive equation with a set of 35 inputs that linked the tariff and the concession period to the internal rate of return (IRR) as the chosen project performance indicator. It was assumed that the two parties had reached an agreement about all other parameters, although no risk allocation was considered.

Because several stakeholders are party to BOT projects and a long period of time may be required to complete the contract, many uncertainties and risks threaten the performance of BOT agreements (Shen, Wu 2005), thus a defined and stable legal and regulatory environment is absolutely necessary (Yuan et al. 2010). In PPP projects, uncertainty or stipulating renegotiation options in contracts may create serious problems, such as opportunistic bidding policies to increase the probability of winning the bid (Chen et al. 2012). The acceptance of a renegotiation petition is equivalent to a possible claim. Jeopardizing public resources by expecting the government to bail out a troubled project company is out of the question, especially in cases of cost overruns or unexpected operating costs due to unqualified management (Ho 2006). Therefore, it is of crucial importance to allocate risk objectively and to identify concession terms in a clear and mutually acceptable manner. Shen et al. (2002) proposed a deterministic model for defining a suitable concession period which strikes a balance among the financial expectations of the various parties concerned. Subsequently, Shen and Wu (2005) modified their pre- vious model by incorporating project risks. The concession period was determined according to the risk and the confidence level in future NPV estimates, but the BOT concession model (BOTCcM) did not reveal the probabilistic combined risk variables which led to the choice of a specific concession period.

Monte Carlo simulation is a computerized risk analysis methodology which generates possible project scenarios using a random selection of input values from specified probability distributions of risk variables. Malini (1999) developed a model incorporating a Monte Carlo simulation technique to perform risk analysis for a BOT project. Policy parameters and macroeconomic indicators were provided as deterministic input variables. Liou and Huang (2008) used Monte Carlo simulation to incorporate project risk and generated 60 input variables for multiple regression analysis to examine the influence of tariffs, concession periods, and borrowing interest rates on net present value (NPV) as the project evaluation indicator. To incorporate a plausible and extensive risk analysis into a BOT project evaluation, it would be helpful to integrate many more scenarios into the determination of concession terms and to perform an objective analysis of various risk variables and their influence.

Statistical soft computing models based on machine learning have been widely used to address a wide range of optimization, classification or prediction problems in different science and engineering applications (Gandomi, Alavi 2009; Yaghouby et al. 2010, 2012; Azamathulla, Ahmad 2013; Najafzadeh, Azamathulla 2014; Gandomi et al. 2013, 2016). One of such models that could be used to automate the decision making scenario is the artificial neural network (ANN) (Jin, Zhang 2011; Sodikov 2005). ANN models have been particularly successful in developing nonlinear data relationships and in enhancing estimates to make more related data available (Emsley et al. 2002).

The ANN approach has been widely used to predict costs in various disciplines where data can be obtained, especially in construction projects (Kim et al. 2004; Gunaydin, Dogan 2004; Tatari, Kucukvar 2011; Fazly et al. 2014). ANN models are capable of learning and simulating elaborate applications (Weckman et al. 2010). Various studies have demonstrated that ANN models provide more accurate estimates than traditional statistical models (Yaghouby et al. 2009; Gandomi, Alavi 2009; Alavi, Gandomi 2011; Hasanzadehshooiili et al. 2012).

In this research, a neural network model was used to develop a model that formulates the relationship between the project's important parameters or risk variables. These were extracted by conducting sensitivity analysis and Monte Carlo simulation on conventional spread sheet data to reach a fair consensus to the government as well as to the concession company. This technique was used on data obtained from six actual BOT dormitory projects in Cyprus as a case study to demonstrate the procedure. 


\section{Significance of research}

It is undeniable fact that professional judgment, skill, and experience play substantial role in implementing PPP versus public procurement because the difference between the two may be relatively narrow. To provide a meaningful value-for-money to convince the parties to undertake BOT type of procurement, a comprehensive and realistic examination of impacts of all quantifiable risks, costs and profits on each other must be included. In order to conduct an analysis to examine viability of an infrastructure project, there should be adequate number of similar past projects to allow forming reliable probability distributions.

Reaching a consensus in contract negotiation requires considering various combinations of concession terms. This typically involves repeated recalculation of conventional financial analysis spreadsheets, which is complex and time-consuming. Earlier studies had developed an automated mechanism and claimed benefits in contract negotiating procedures. However, in these studies, either risk allocation was not considered (Ngee et al. 1997), or inadequate information was given on probable combinations of risk variables (Shen, Wu 2005). Some researchers have used IRR as a decision-making criterion (Ng et al. 2007); although, NPV is a more objective criterion, and project appraisal using both criteria helps to avoid misleading judgments.

Previous studies focused attention on project construction cost among the concession terms (Yang et al. 2007), but in addition, a model should present toll/tariff rates or other fundamental parameters which define decision-making boundaries for the host government.

Incorporating extensive risk analysis into a BOT project evaluation requires a tool to help integrate many probable scenarios into the determination of concession terms and to perform an objective analysis of various risk variables and their influence. With the help of an ANN model, this research attempted to incorporate as many scenarios as could be generated. Both NPV and IRR were considered to ensure the most unbiased results. The ANN model could identify relationships between input variables and help create an accurate decision-making model, including an extensive risk analysis. The results of this study show that by defining specific concession terms (favorable to both parties), it is possible to estimate an appropriate value of price/student/year using the ANN method. Therefore, an approach is proposed by this research to develop a model that formulates the relationship between project's important parameters or risk variables by utilizing ANN model's capabilities to help professionals examine viability of undertaking a BOT type project.

\section{Methodology}

Conventional financial analysis spread sheets are computed in MS Excel 2007 using actual data. After examining the impact of changing the concession period on the project performance indicators (IRR and NPV), several concession periods with substantial impacts are chosen to compute cash flows. Conventional spread sheets are calculated to perform cash flow analysis for selected concession periods.

The risk variables with the most crucial impact on the project outcome are identified from sensitivity analysis. Those parameters that substantially affected the variability of the proposed project outcomes would be identified as uncertain and risky variables.

Next, Monte Carlo simulation is performed on the conventional spread sheets to conduct risk analysis. The probability distributions and the likely ranges of risk variables (identified by sensitivity analysis) would be assumed according to historical observations. Monte Carlo analysis software is capable of selecting random values of uncertain/risk variables in a range of specified probability distributions, generating random scenarios and a series of possible project outcomes. This procedure is basically repeated 10,000 times, yielding a probability distribution of outcomes. The expected project outcomes or risk forecasts are expressed as NPV and IRR.

With consideration of eligible ranges for NPV and IRR, generated random scenarios in Monte Carlo simulation are used to draw data inputs for the ANN model. This information is fed into the ANN model to create an automated prediction model that could provide accurate results to reach unanimous decision criteria which would satisfy the requirements of all parties simultaneously. In the following section, a demonstration of this procedure on data from six actual BOT dormitory projects in Cyprus will be described.

\section{Case study}

Turkey and Northern Cyprus are among the countries that have embraced the BOT model to provide necessary investments. The economy of Northern Cyprus is highly dependent on the education sector, which is expected to expand in the coming years. In 2011, Northern Cyprus received $\$ 400$ million in revenues from this sector (Ocakoglu 2011), and therefore investment in student accommodations is of great importance.

Six university dormitories built in Northern Cyprus under BOT agreements with different concession terms were chosen as a case study. The authors obtained actual data related to the dormitory projects. All nominal values were converted to real values according to actual inflation rates published by the government. Information about the dormitories is shown in Table 1.

\section{Preparing conventional spread sheets}

Conventional financial analysis spread sheets for the six dormitories were computed in MS Excel 2007 using actual data. After analysing the impact of different concession periods on the project performance indicators (IRR and NPV), it was decided to compute cash flows for four concession periods with substantial impact on the project performance indicators: 15, 20, 25, and 30 years. Overall, 
Table 1. Information about the dormitories

\begin{tabular}{ccccc}
\hline Dormitory & $\begin{array}{c}\text { Total Area } \\
\left(\mathrm{m}^{2}\right)\end{array}$ & $\begin{array}{c}\text { Number } \\
\text { of Rooms }\end{array}$ & $\begin{array}{c}\text { Number } \\
\text { of Beds }\end{array}$ & $\begin{array}{c}\text { Construction } \\
\text { Period }\end{array}$ \\
\hline 1 & 3500 & 66 & 204 & $1989-1990$ \\
2 & 4300 & 66 & 220 & $1990-1991$ \\
3 & 7412 & 125 & 253 & $1989-1990$ \\
4 & 4992 & 192 & 352 & 2005 \\
5 & 3339 & 72 & 312 & 2006 \\
6 & 1182 & 40 & 80 & $1989-1990$ \\
\hline
\end{tabular}

24 conventional spread sheets were computed for cash flow analysis of these concession periods. This meant that some of the calculations had to be projected into future years. Up to 2012, all the information in the spread sheets is actual data which were acquired from the head office of each dormitory. Data for future years were calculated according to the observed trend of changes in previous years.

\section{Monte Carlo simulation and sensitivity analysis}

Monte Carlo simulation was performed on the 24 spread sheets using the Chart FX Crystal Ball 7.3 computerbased software to carry out risk analysis. The risk variables with the most crucial impact on the outcome of the project were obtained from sensitivity analysis of the conventional spread sheets using MS Excel 2007.

Sensitivity carries out a clear and adjustable procedure by varying the parameters randomly one at a time to observe the impact of changes on the outcome. For any given parameter a number of incremental changes are made and the final indicator value (outcome) is computed each time recording the degree of change from its baseline (Jenkins et al. 2011). Variables that their variation could have a dramatic impact on the projects' outcome will be chosen as input variables to Mote Carlo Simulation.
In this study, three parameters substantially affected the variability of the proposed project outcomes and were identified as uncertain and risky variables: cost overrun factor, occupancy rate, and price/year/student. The probability distributions and the likely ranges of the selected risk variables were assumed according to historical observations and are presented in Table 2.

Customized Monte Carlo Simulation software enabled the computer to select random values in the range of specified probability distributions to generate random project scenarios and a series of possible project outcomes. This procedure was repeated 10,000 times, resulting in a probability distribution of outcomes.

The expected project outcomes or risk forecasts were expressed as NPV and IRR values. As an example, a single forecast for one of the university dormitories with a specific concession period is shown in Figure 1.

\section{Sampling procedures}

On the basis of random project scenarios generated with Monte Carlo simulation considering eligible ranges for NPV and IRR along with other parameters that seemed important from a decision maker point of view, eight input values (capital expenditure cost overrun factor, occupancy rate, NPV, IRR, total dormitory area, number of rooms, number of beds, and concession period) were selected as input variables. Price/year/student (\$) was used as the output variable.

1871 different scenarios associated with actual BOT dormitory projects for universities in Cyprus were generated. This information was fed into the ANN model to create a model that could automate the negotiation process for BOT-type dormitory projects and that could determine the optimal price/year/student according to unanimous decision criteria which would satisfy the requirements of all parties simultaneously (Fig. 2).

Table 2. Risk variables and probability distribution

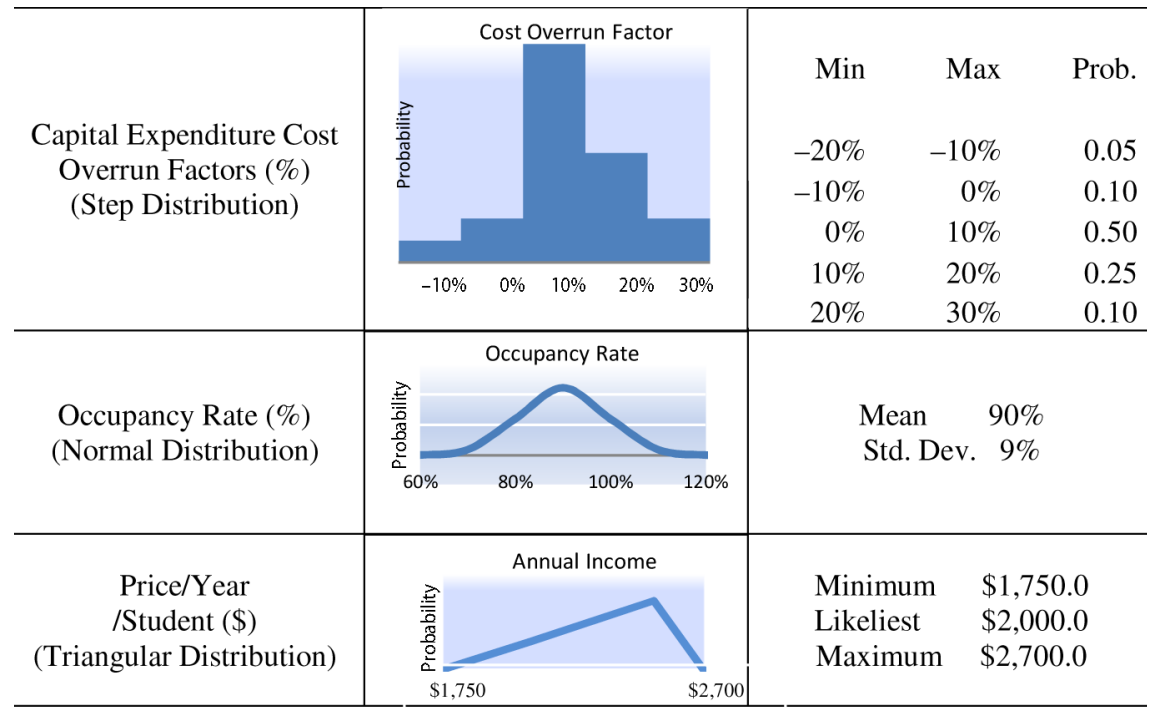




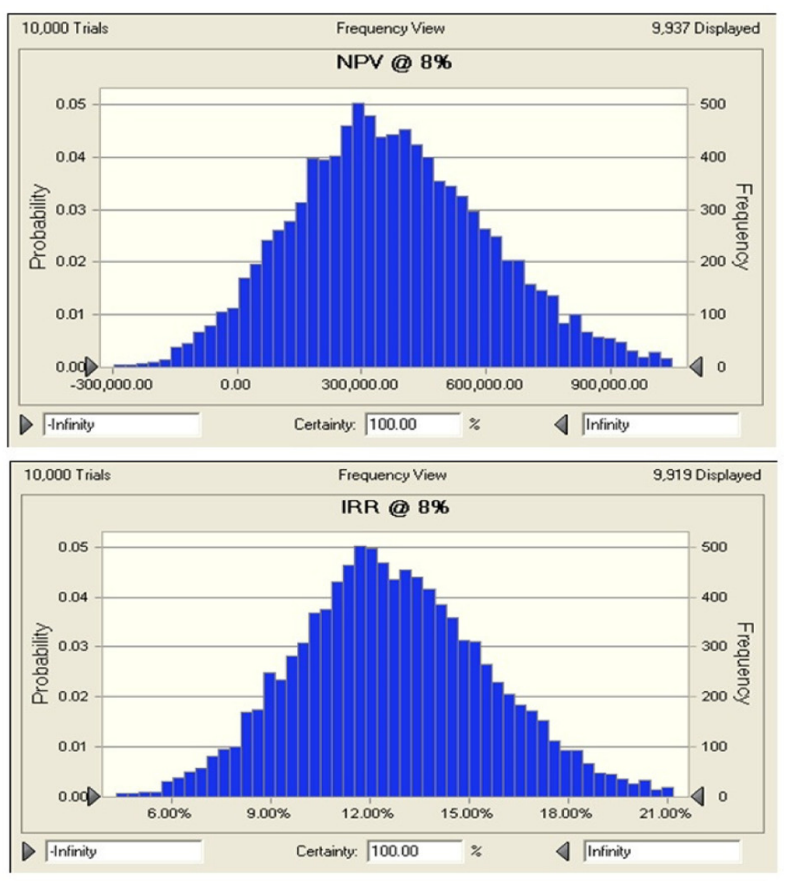

Fig. 1. Example frequency probability distributions of NPV and IRR

The conditions defined to extract data as input values for the ANN model are:

- The eligible ranges for IRR (greater than the discount rate (8\%) and NPV (greater than zero) were obtained from the Monte Carlo simulation.

- The eligible range for risk variables mentioned above were probability distributions extracted from historical observations.

\section{Artificial neural network}

Neural network models are comprised of simple computational units structured into layers and interwoven by a system of connections. ANN is developed in three layers; an input layer, hidden layer(s), and an output layer. The number of hidden layers changes according to the application (Dikmen, Sonmez 2011). The output layer receives the input and signals flow from the input layer through the hidden layers which are between the output and input layers (Apanaviciene, Juodis 2003).

Each layer consists of several neurons, which are interconnected by sets of correlation weights. The input layer's neurons receive their activation from the environment, while the activation levels of neurons in the hidden and output layers are computed as a function of the activation levels of the neurons feeding into them. The information which is received as inputs will be transferred to the hidden layer, and produce an output with the transfer function. Additionally, the learning processing (or training) is formed by adjusting the weight of interconnectivity neurons. The training data set is continuously looped through the network and after every predefined number of iterations; the test set data is passed through the evolved network to generate an output. Then the error of each neuron is calculated. The training is stopped as the error fall to a lower value than the target value. The total error is evaluated by adding up all the errors for each individual neuron and then for each pattern in turn to give a total error. The network keeps training until the total errors falls to some pre-determined low target value and then it stops. Once the network has been fully trained, the test set which is different than the training set is used to check the validation networks (Baalousha, Çelik 2011).

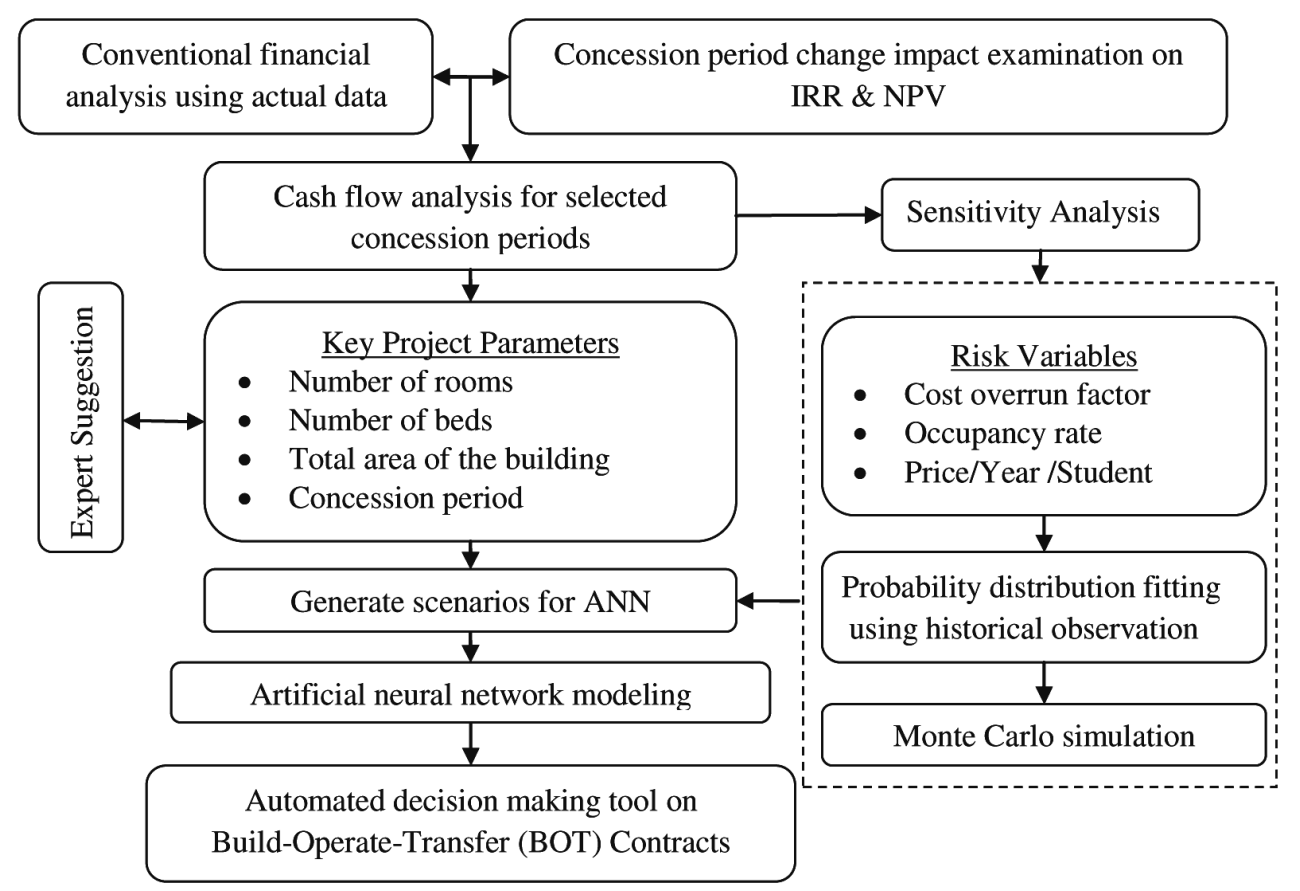

Fig. 2. Sampling procedure for ANN model 


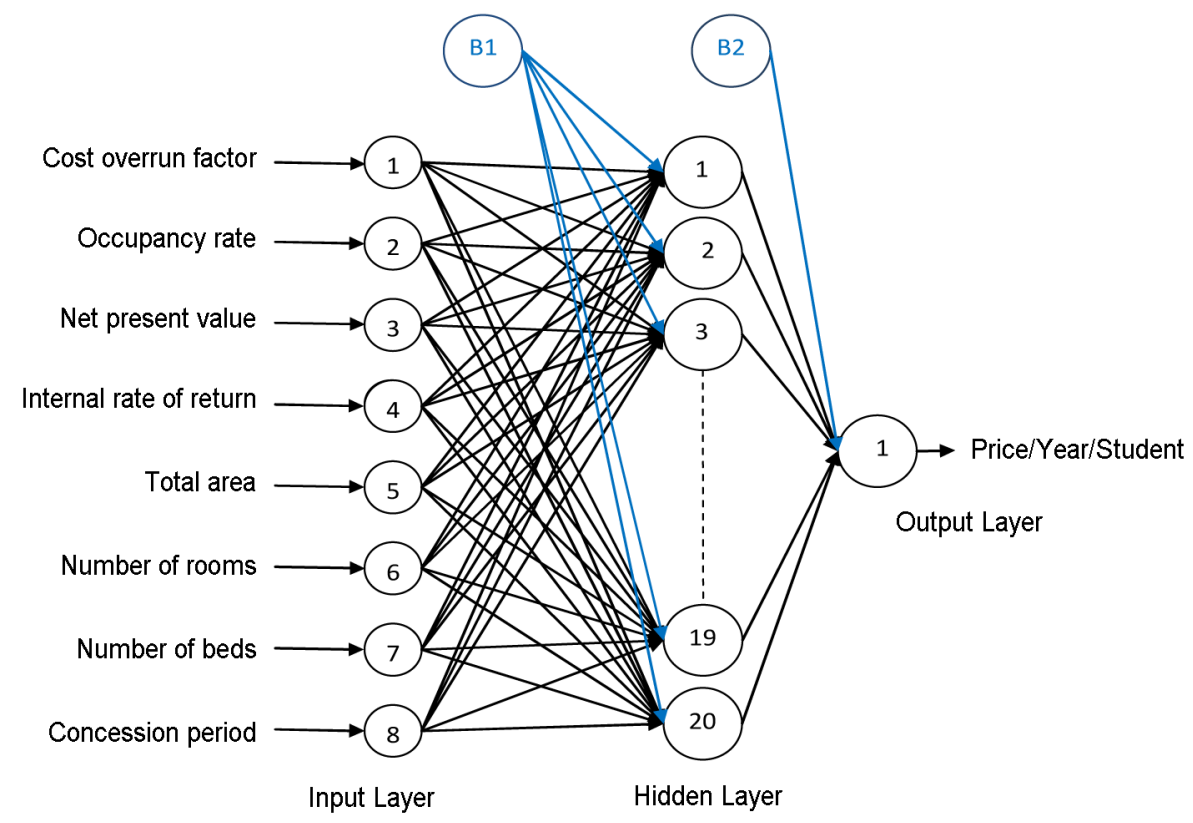

Fig. 3. Artificial neural network architecture

In this study 1780 data sets ( $80 \%$ of the data) were used to train the ANN model, while the remaining data sets were used as test data. A two-layer feed forward network with sigmoid hidden neurons and linear output neurons was found to fit multidimensional mapping problems sufficiently well, given consistent data and enough neurons in the hidden layer. The network was trained using the Levenberg-Marquardt back-propagation algorithm unless there was not enough memory, in which case scaled conjugate-gradient back-propagation was used. The ANN model was built with a hidden layer and dataset using the 8-20-1 architecture, which contains eight nodes in the input layer, 20 nodes in the hidden layer, and one node in the output layer (Fig. 3). MathWorks MATLAB R2010b, ANN Toolbox software was used for the analysis. The data sets were divided into three groups: training data, cross-validation data, and a test data set according to the following percentages:

1. Training set $-80 \%$;

2. Cross-validation $-10 \%$;

3. Test set $-10 \%$.

\section{Results and discussion}

Table 3 shows an example of the training data which were used to train the network by determining values for the parameters (weights). Cross-validation was used to monitor the capability of the neural network to build generalized outputs and to eliminate data memorization risk. Finally, test data were used to validate the quality of the chosen ANN model. Scarce or overly simple training data produce large training and testing errors, resulting in under-fitting. Complex and ambiguous models constructed using noisy or corrupted training data create low training errors, but their testing errors cannot be ignored. Stopping criteria and weight resetting were used to cope with under- and over-fitting problems (Sodikov 2005; Smith, Mason 1997).

A comparison of training and testing data was performed as illustrated in Figure 4 and showed a close fit between predicted and measured values. The three axes represent training, validation, and testing data. The dashed line in each dimension represents a perfect relationship between outputs and targets, the solid line represents the best-fit linear regression line, and the R-value indicates the strength of the relationship. In this study, the training data achieved a good fit, and the validation and test results also yielded R-values greater than 0.9. Training was stopped after the validation error increased for six iterations, which occurred at iteration 32 .

Table 3. Example of training data set

\begin{tabular}{cccccccccc}
\hline \multicolumn{1}{c}{$\begin{array}{c}\text { Cost overrun } \\
\text { factor }(\%)\end{array}$} & $\begin{array}{c}\text { Occupancy } \\
\text { rate }(\%)\end{array}$ & NPV & $\begin{array}{c}\text { IRR } \\
(\%)\end{array}$ & $\begin{array}{c}\text { Total area } \\
\left(\mathrm{m}^{2}\right)\end{array}$ & $\begin{array}{c}\text { Number of } \\
\text { rooms }\end{array}$ & $\begin{array}{c}\text { Number of } \\
\text { beds }\end{array}$ & $\begin{array}{c}\text { Concession } \\
\text { period (years) }\end{array}$ & $\begin{array}{c}\text { Output } \\
\text { Price/year/ } \\
\text { student }(\$)\end{array}$ \\
\hline-20 & 95 & 230000 & 10.4 & 7412 & 125 & 253 & 25 & 1750 \\
\hline 0 & 100 & 244760 & 11.0 & 4992 & 192 & 352 & 20 & 1950 \\
\hline 10 & 90 & 437100 & 15.6 & 3339 & 72 & 312 & 30 & 2000 \\
\hline-10 & 85 & 90470 & 10.3 & 4300 & 66 & 200 & 15 & 2200 \\
\hline
\end{tabular}



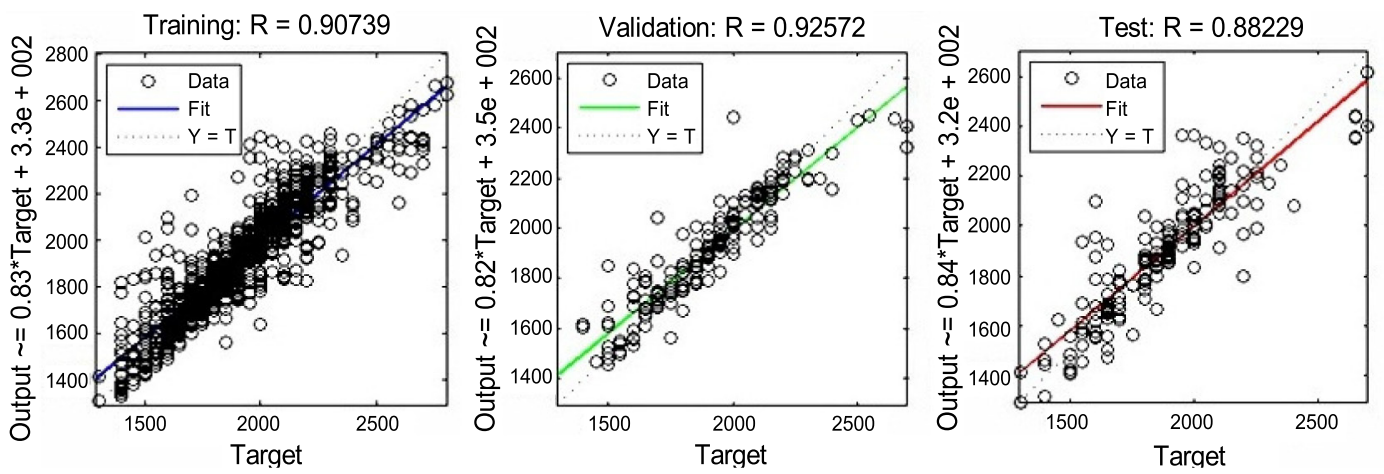

Fig. 4. Training, validation, and test data

Figure 5 shows a plot of the training, validation, and test errors. In this example, the results can be viewed as reasonable because of the following considerations:

- The final mean squared error is small.

- The test set and validation set errors have similar characteristics.

- No significant over-fitting has occurred by iteration 26 (when the best validation performance occurs).

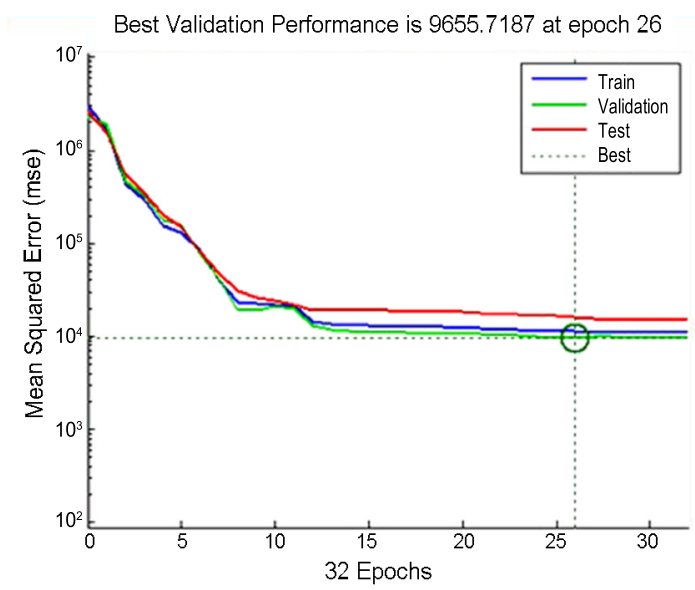

Fig. 5. Training, validation, and test root mean squared error values

In addition, examples of test data for different priceestimation status values were also calculated as illustrated in Figure 6. By projecting each input value against its output value, the accuracy of using ANN as a comprehensive price estimation tool can be evaluated. Note that the trends in the graphs reflect all eight input values simultaneously, not just the projected input value. By using these link weights from a trained ANN, the price/year/ student can be estimated. The errors and correlations for

Table 4. Errors and correlations

\begin{tabular}{c|c|c|c}
\hline RMSE & MAE & $\mathrm{R}$ & $\rho$ \\
\hline 108.0841 & 71.287 & 0.9064 & 0.029477 \\
\hline
\end{tabular}

RMSE: root mean square error; MAE: mean absolute error; $\mathrm{R}$ : correlation coefficient; $\rho$ : performance index (Gandomi, Roke 2013).
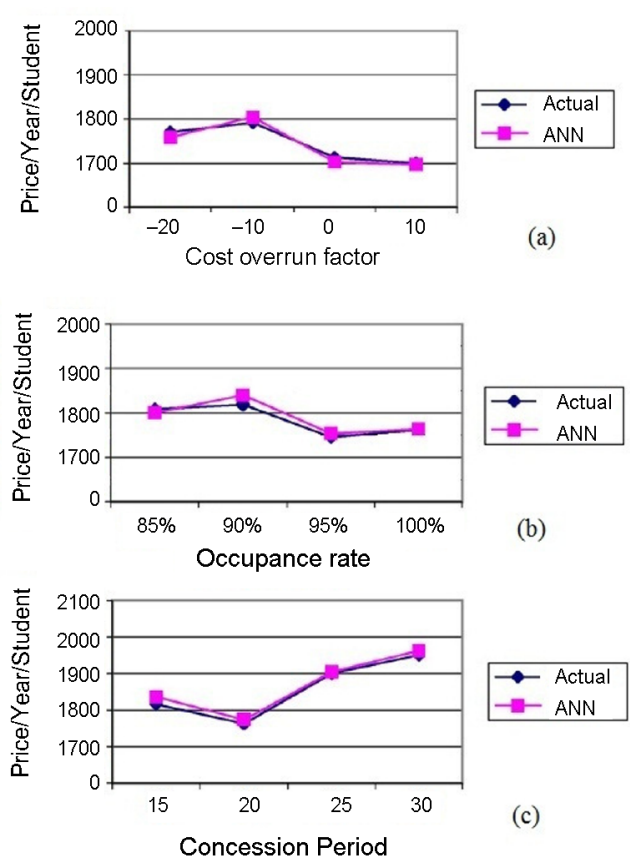

Fig. 6. Test data for evaluating price/year/student: (a) cost overrun factor; (b) occupancy rate; (c) concession period

the whole data sets are presented on Table 4. This study can be reproduced and applied to other projects as well.

\section{Conclusions}

The results of this study show that by defining specific concession terms (favourable to both parties), it is possible to estimate an appropriate value of price/student/ year using the ANN method. Using actual data for dormitories in Cyprus helped demonstrate how to incorporate risk attributes and relevant parameters into the model formulation process to identify possible combinations of financial terms in a BOT project. On the basis of actual cash flow statements for six university dormitory construction projects and considering 15-, 20-, 25-, and 30year concession periods for each, 24 conventional spread sheets were prepared to compute net present value (NPV) and internal rate of return (IRR) as project performance 
indicators for the various concession periods. With incorporating data sets drawn from Monte Carlo simulation and several important parameters on all the spread sheets, 1871 random scenarios were produced, and each scenario with a selected set of eight input variables (capital expenditure cost overrun factor, occupancy rate, NPV, IRR, total dormitory area, number of rooms, number of beds, and concession period) was fed into the ANN. The ANN approach succeeded in automating the negotiation process for a BOT-type contract by taking into account project risks and uncertainties along with several important parameters to build an unbiased and accurate pricing structure for BOT-type projects.

\section{Acknowledgements}

The first author would like to thank Dr Iman Aghayan for his help.

\section{Disclosure statement}

Authors do not have any competing financial, professional, or personal interests from other parties.

\section{References}

Akintoye, A. 2009. PPPs for physical infrastructure in developing countries, in Policy, management and finance of public private partnerships. New York: Wiley, 123-144.

Akintoye, A.; Beck, M.; Hardcastle, C. (Eds.). 2003. Publicprivate partnerships: managing risks and opportunities. Oxford, UK: Blackwell Science Ltd. 448 p. http://dx.doi.org/10.1002/9780470690703

Alavi, A. H.; Gandomi, A. H. 2011. Prediction of principal ground-motion parameters using a hybrid method coupling artificial neural networks and simulated annealing, Computers and Structures 89(23-24): 2176-2194. http://dx.doi.org/10.1016/j.compstruc.2011.08.019

Apanaviciene, R.; Juodis, A. 2003. Construction project management effectiveness modelling with neural networks, Journal of Civil Engineering and Management 9(1): 5967. http://dx.doi.org/10.1080/13923730.2003.10531302

ASHRAE. 2006. ASHRAE green guide: the design, construction, and operation of sustainable buildings. American Society of Heating, Refrigerating Air-conditioning Engineers, Atlanta, GA. 488 p.

Azamathulla, H. M.; Ahmad, Z. 2013. Estimation of critical velocity for slurry transport through pipeline using adaptive neuro-fuzzy interference system and gene-expression programming, Journal of Pipeline Systems Engineering and Practice 4(2): 131-137.

http://dx.doi.org/10.1061/(ASCE)PS.1949-1204.0000123

Baalousha, Y.; Çelik, T. 2011. An integrated web-based data warehouse and artificial neural networks system for unit price analysis with inflation adjustment, Journal of Civil Engineering and Management 17(2): 157-167. http://dx.doi.org/10.3846/13923730.2011.576806

Chen, T.-C.; Lin, Y.-C.; Wang, L.-C. 2012. The analysis of BOT strategies based on game theory- case study on Taiwan's high speed rail way project, Journal of Civil Engineering and Management 18(5): 662-674.

http://dx.doi.org/10.3846/13923730.2012.723329

Dikmen, U. S.; Sonmez, M. 2011. An artificial neural networks model for the estimation of formwork labour, Journal of Civil Engineering and Management 17(3): 340-347. http://dx.doi.org/10.3846/13923730.2011.594154
Emsley, M. W.; Lowe, D. J.; Duff, A. R.; Harding, A.; Hickson, A. 2002. Data modeling and the application of a neural network approach to the prediction of total construction cost, Construction Management and Economics 20(6): 465-472. http://dx.doi.org/10.1080/01446190210151050

Fazly, M.; Azamathulla, H. M.; Rozi, A. 2014. Prediction of soil erodibility factor for Peninsular Malaysia soil series using ANN, Neural Computing \& Applications 24(2): 383-389. http://dx.doi.org/10.1007/s00521-012-1236-3

Gandomi, A. H.; Alavi, A. H. 2009. Applications of computational intelligence in behavior simulation of concrete materials, in Computational optimization and applications in engineering and industry, SCI Vol. 359. Springer, 221-224.

Gandomi, A. H.; Roke, D. A. 2013. Intelligent formulation of structural engineering systems, in Seventh M.I.T. Conference on Computational Fluid and Solid Mechanics - Focus: Multiphysics \& Multiscale, 12-14 June 2013, Massachusetts Institute of Technology, Cambridge, MA. 5 p.

Gandomi, A. H.; Yang, X.; Talatahari, S.; Alavi, A. H. 2013. Metaheuristics in modeling and optimization, in $\mathrm{Me}$ taheuristic applications in structures and infrastructures. Waltham, MA: Elsevier, 1-24.

http://dx.doi.org/10.1016/B978-0-12-398364-0.00001-2

Gandomi, M.; Soltanpour, M.; Zolfaghari, M. R.; Gandomi, A. H. 2016. Prediction of peak ground acceleration of Iran's tectonic regions using a hybrid soft computing technique, Geoscience Frontiers 7(1): 75-82. http://dx.doi.org/10.1016/j.gsf.2014.10.004

Grimsey, D.; Lewis, M. K. 2004. Public private partnerships: the worldwide revolution in infrastructure provision and project finance. Edvard Elgar, UK. 288 p. http://dx.doi.org/10.4337/9781845423438

Gunaydin, H. M.; Dogan, S. Z. 2004. A neural network approach for early cost estimation of structural systems of buildings, International Journal of Project Management 22(7): 595-602.

http://dx.doi.org/10.1016/j.ijproman.2004.04.002

Hasanzadehshooiili, H.; Lakirouhani, A.; Medzvieckas, J. 2012. Superiority of artificial neural networks over statistical methods in prediction of the optimal length of rock bolts, Journal of Civil Engineering and Management 18(5): 655-661. http://dx.doi.org/10.3846/13923730.2012.724029

Ho, S. P. 2006. Model for financial renegotiation in publicprivate partnership projects and its policy implications: game theoric view, Journal of Construction Engineering and Management 132(7): 678-688.

http://dx.doi.org/10.1061/(ASCE)0733-9364(2006)132:7(678)

Jenkins, G.; Kuo, C. Y.; Harberger, A. C. 2011. Cost-Benefit analysis for investment decisions. Chapter 8. Kingston: Queen's University. 39 p.

Jin, X. H.; Zhang, G. 2011. Modelling optimal risk allocation in PPP projects using artificial neural networks, International Journal of Project Management 29(5): 591-603. http://dx.doi.org/10.1016/j.ijproman.2010.07.011

Kim, G.-H.; Yoon, J.-E.; An, S.-H.; Cho, H.-H.; Kang, K.-I. 2004. Neural network model incorporating a genetic algorithm in estimating construction costs, Building and Environment 39(11): 1333-1340.

http://dx.doi.org/10.1016/j.buildenv.2004.03.009

Liou, F. M.; Huang, C. P. 2008. Automated approach to negotiations of BOT contracts with the consideration of project risk, Journal of Construction Engineering and Management 134(1): 18-24.

http://dx.doi.org/10.1061/(ASCE)0733-9364(2008)134:1(18)

Malini, E. 1999. Build operate transfer municipal bridge projects in India, Journal of Management in Engineering 15(4): 51-58.

http://dx.doi.org/10.1061/(ASCE)0742-597X(1999)15:4(51) 
Najafzadeh, M.; Azamathulla, H. M. 2014. Neuro-fuzzy GMDH to predict the scour pile groups due to waves, Journal of Computing in Civil Engineering, 04014068.

Ngee, L.; Tiong, R. L. K.; Alum, J. 1997. Automated approach to negotiation of BOT contracts, Journal of Computing in Civil Engineering 11(2): 121-128.

http://dx.doi.org/10.1061/(ASCE)0887-3801(1997)11:2(121)

Ng, S. T.; Xie, J.; Cheung, Y. K.; Jefferies, M. 2007. A simulation model for optimizing the concession period of public-private partnerships schemes, International Journal of Project Management 25(8): 791-798. http://dx.doi.org/10.1016/j.ijproman.2007.05.004

Ocakoglu, O. G. 2011. Zaman [online], [cited 20 October 2011]. Available from Internet: www.zaman.com.tr.

Shen, L.; Li, H.; Li, Q. 2002. Alternative concession model for build/operate/transfer contract projects, Journal of Construction Engineering and Management 128(4): 326-330.

http://dx.doi.org/10.1061/(ASCE)0733-9364(2002)128:4(326)

Shen, L. Y.; Wu, Y. Z. 2005. Risk concession model for build/ operate/transfer contract projects, Journal of Construction Engineering and Management 131(2): 211-220.

http://dx.doi.org/10.1061/(ASCE)0733-9364(2005)131:2(211)

Smith, A.; Mason, A. 1997. Cost estimation predictive modelling: regression versus neural network, Engineering Economist 42(2): 137-161. http://dx.doi.org/10.1080/00137919708903174

Sodikov, J. 2005. Cost estimation of highway projects in developing countries: artificial neural network approach, Journal of the Eastern Asia Society for Transportation Studies 6: 1036-1047.

Tatari, O.; Kucukvar, M. 2011. Cost premium prediction of certified green buildings: a neural network approach, Building and Environment 46(5): 1081-1086.

http://dx.doi.org/10.1016/j.buildenv.2010.11.009
Weckman, G. R.; Paschold, H. W.; Dowler, J. D.; Whiting, H. S.; Young, W. A. 2010. Using neural networks with limited data to estimate manufacturing cost, Journal of Industrial and Systems Engineering 3(4): 257-264.

Xenidis, Y.; Angelides, D. 2005. The financial risks in buildoperate-transfer projects, Construction Management and Economics 23(4): 431-441. http://dx.doi.org/10.1080/01446190500041552

Yaghouby, F.; Ayatollahi, A.; Bahramali, R.; Yaghouby, M.; Alavi, A. H. 2010. Towards automatic detection of atrial fibrillation: a hybrid computational approach, Computers in Biology and Medicine 40(11-12): 919-930. http://dx.doi.org/10.1016/j.compbiomed.2010.10.004

Yaghouby, F.; Ayatollahi, A. B. R.; Yaghouby, M. 2012. Robust genetic programming-based detection of atrial fibrillation using RR intervals, Expert Systems 29(2): 183-199. http://dx.doi.org/10.1111/j.1468-0394.2010.00571.x

Yaghouby, F.; Ayatollahi, A.; Soleimani, R. 2009. Classification of cardiac abnormalities using reduced features of heart rate variability signal, World Applied Science Journal 6(11): 1547-1554.

Yang, Y.; Guo, M.; Hu, W. 2007. Effect of diversification of operation cost on infrastructure BOT project investment decision and analysis of option game, China Population, Resources and Environment 17(2): 32-35.

Yuan, J.-F.; Skibniewski, M. J.; Li, Q.; Shan, J. 2010. The driving factors of China's public-private partnership projects in Metropolitian transportation systems: public sector's viewpoint, Journal of Civil Engineering and Management 16(1): 5-18. http://dx.doi.org/10.3846/jcem.2010.01

Zhang, X. Q.; Kumaraswamy, M. M. 2001. Hong Kong experience in managing BOT projects, Journal of Construction Engineering and Management 127(2): 154-162.

http://dx.doi.org/10.1061/(ASCE)0733-9364(2001)127:2(154)

Neda SHAHRARA. She received her PhD from Eastern Mediterranean University, North Cyprus. She is a Civil Engineer at the City of San Diego, California, USA. Her research interests include Public Private Partnership (PPP), investment appraisal, project cost estimation and life cycle costing.

Tahir ÇELIK. He is a professor in the Civil Engineering Department at Cyprus International University, North Cyprus. He is the founder and the director of Construction Engineering and Management Program. His research interests include quality management, life cycle costing, estimating construction projects, construction planning and construction techniques.

Amir H. GANDOMI. He received his PhD from University of Akron, OH. He was selected as an elite in 2008 by National Elites Foundation. He used to be a lecturer in several universities, and he is currently a distinguished research fellow in an NSF center for the study of evolution in action (BEACON) located at Michigan State University, MI. Dr Gandomi has published over one hundred journal papers and four books. Some of those publications are now among the hottest papers in the field, and collectively have been cited more than 5,000 times (h-index $=37$ ). He also served as associate editor, editor and guest editor in several prestigious journals. His research interests are evolutionary computations and their applications in (big) data mining and optimization of engineering systems. 